\title{
A new in vitro method for the estimation of digestibility using the intestinal fluid of the pig
}

\author{
By S. FURUYA, K. SAKAMOTO* AND S. TAKAHASHI \\ Department of Nutrition, National Institute of Animal Industry, Chiba-shi 280, Japan
}

(Received 24 April 1978 - Accepted I9 July 1978)

I. A new in vitro method using the intestinal fluid of the pig for predicting the digestibility of diets was proposed.

2. A $0.5 \mathrm{~g}$ sample of pig diet was placed in a $100 \mathrm{ml}$ Erlenmeyer flask, $20 \mathrm{mg}$ pepsin $(E C 3.4 .4 .1)$ in $10 \mathrm{ml} 0.075 \mathrm{M}$-hydrochloric acid was added, and the mixture was incubated for $4 \mathrm{~h}$ at $37^{\circ}$. Then, after neutralization with $0.2 \mathrm{M}$-sodium hydroxide, $10 \mathrm{ml}$ of intestinal fluid was added and incubated for an additional $4 \mathrm{~h}$ at $37^{\circ}$. This fluid was obtained from a pig fitted with a simple cannula in the upper jejunum. After the two-stage incubations, the contents of the flask was centrifuged for $10 \mathrm{~min}$ at $1250 \mathrm{~g}$ and the residue transferred to preweighed filter paper for dry matter (DM) and crude protein (nitrogen $\times 6.25 ; \mathrm{CP}$ ) determinations. The in vitro DM and CP digestibility was calculated on the basis of the original DM and CP content of the diet respectively.

3. The intestinal fluid could be stored at $-20^{\circ}$ for $60 \mathrm{~d}$ without losing its activity on DM and CP digestion.

4. A high correlation was found between this in vitro method and the standard in vivo procedures, for seven diets commonly used for growing or adult pigs, when diets were ground to pass through a $\mathrm{Imm}$ screen for the in vitro experiment, but there was an obvious dissimilarity between the two methods, especially in the case of CP: DM, $Y=1.04 X+0.0806(r 0.98, P<0.01) ; C P, Y=1.70 X-0.6092(r 0.98, P<0.01)$, where $Y$ and $X$ are in vivo and in vitro digestibility respectively.

5. This method is rapid and reproducible and particularly suited for the evaluation of a large number of samples. Since this method assesses only stomach and small intestinal digestion, it therefore may require further modification when used for diets which include large amounts of crude fibre. Also, depending on the needs of the investigator, the addition of a correction factor for endogenous faecal nitrogen loss may be required.

Digestibility experiments with animal diets have considerable value in the estimation of their nutritive value. Although indicator methods commonly used in the digestibility experiments for simple-stomached animals have the advantage that they do not require the measurement of food intake and faeces output, the determination of the digestibility is still both tedious and time-consuming and requires large quantities of diets.

In vitro techniques with rumen fluid or semi-purified enzyme preparations, or both have been widely used for the evaluation of ruminant feeds (Osbourn \& Terry, 1977), but there has apparently been no attempt to use intestinal fluid for digestibility studies in simplestomached animals.

In simple-stomached animals, such as the pig, digestion of major dietary components starts in the stomach and is essentially completed in the small intestine (Holmes et al. 1973; Keys \& DeBarthe, 1974; Furuya \& Takahashi, 1975a). During the intestinal phase of digestion the soluble pancreatic enzymes hydrolyze dietary components to the terminal stage just preceeding final hydrolysis or absorption by brush-border-bound systems or both (Rerat et al. 1976). In the stomach phase of digestion, hydrochloric acid and pepsin $(E C 3 \cdot 4 \cdot 4.1)$ are the hydrolyzing agents. Both are commercially available. In the intestinal phase of digestion, the soluble pancreatic enzymes, bile salts and perhaps other minor components of the pancreatic and liver secretions are obtainable in the intestinal fluid. Therefore, it is reasonable that digestibility of diets may be estimated by an in vitro method,

* Present address: Nippon Kayaku Co. Ltd, Takasaki-shi 370-12, Japan. 
if the actual digestion occurring in the stomach and the small intestine can be simulated.

The objectives of the experiments reported in this paper were to establish an in vitro digestion method which is based on the incubation of test substrate (food) with acid pepsin followed by intestinal fluid obtained from the pig, thus simulating stomach digestion followed by intestinal digestion. Also, the in vitro method was compared with the in vivo method for the determination of the dry matter (DM) and crude protein (nitrogen $\times 6.25 ; \mathrm{CP}$ ) digestibility in pig diets.

\section{EXPERIMENTAL}

\section{Diets}

Diets A, B, C and D were used as standard diets in this study (Tables I and 2). The four standard diets are routinely used in our laboratory. Diet $\mathrm{A}$ is generally used for early-weaned pigs, diets $\mathrm{B}$ and $\mathrm{C}$ for growing pigs and diet $\mathrm{D}$ for adult pigs. An additional four commercial diets (diets E, F, G and H) were also tested. Since the ingredients of the commercial diets were not clear, only their chemical composition is shown in Table 2.

\section{Preparation of intestinal fluid}

A female Pitman-Moore mini-pig weighing approximately $25 \mathrm{~kg}$ was used as a host animal to obtain the intestinal fluid for in vitro digestion experiments. The pig was fitted with a simple (' $\mathrm{T}$ '-shaped) cannula in the upper jejunum $500 \mathrm{~mm}$ beyond the pylorus and distal to the common bile duct. The surgical technique was similar to that described in a previous paper (Furuya \& Takahashi, 1975b). The pig was maintained in a metabolism cage which allowed free movement and was housed in an animal room with the temperature controlled at $23-25^{\circ}$. The pig was given food and water once daily at 08.30 hours, $500 \mathrm{~g}$ diet $B$ and 21 water.

Approximately $500 \mathrm{~g}$ of intestinal contents were removed daily between $\mathrm{I} 0.00$ and I $\mathrm{I} .00$ hours through the cannula and centrifuged for $10 \mathrm{~min}$ at $1250 \mathrm{~g}$. The supernatant fraction (intestinal fluid) was used immediately or stored at $-20^{\circ}$ for in vitro digestion experiments. The same batch of intestinal fluid was used in each experiment.

\section{Experimental in vitro procedures}

Experimental conditions were determined in Expts $1-5$ and the standard procedures were developed from these results.

Expt I. Effect of pepsin concentration and incubation period in the first stage of the in vitro method. Pepsin concentration and incubation period in the first stage were examined with standard diets A and D. Pepsin from pig stomach mucosa was purchased from Sigma Chemical Co, Saint Louis, USA. The activity was 700-1000 units per $\mathrm{mg}$ protein, where I unit will produce an $\mathrm{A}_{280}$ of $0.00 \mathrm{I}$ per min at $\mathrm{pH} 2.0$ at $37^{\circ}$, measured as TCA-soluble products, using haemoglobin as substrate. Pepsin concentrations tested were $0 . \mathrm{I}$ and $2 \mathrm{~g} / \mathrm{l}$ $0.075 \mathrm{M}$-hydrochloric acid. The former concentration was suggested by Akeson \& Stahmann (I964) and the latter by the Association of Official Analytical Chemists (I970). At each pepsin concentration the selected incubation periods were $0,2,4$ and $6 \mathrm{~h}$. The other experimental conditions were identical to the standard procedures.

Expt 2. Effect of incubation period in the second stage of the in vitro method. Incubation period in the second stage was examined with the four standard diets. The selected incubation periods were $0,2,4$ and $6 \mathrm{~h}$. The other experimental conditions were identical to the standard procedures.

Expt. 3. Effect of storing of the intestinal fluid on in vitro digestibility. Effect of storing of the intestinal fluid on in vitro digestibility was examined with diet $\mathrm{C}$. The intestinal fluid, 
Table I. Ingredients of the standard diets $(\mathrm{g} / \mathrm{kg})$

\begin{tabular}{|c|c|c|c|c|}
\hline \multirow[b]{2}{*}{ Ingredient } & \multicolumn{4}{|c|}{ Diet } \\
\hline & A & B & C & $\mathrm{D}$ \\
\hline Ground maize & - & $435 \cdot 5$ & 220 & 360 \\
\hline Sorghum grain & - & 100 & 220 & - \\
\hline Barley meal & - & - & 220 & 270 \\
\hline Wheat meal & 415 & 150 & - & - \\
\hline Wheat offal & - & - & $121 \cdot 5$ & $176 \cdot 5$ \\
\hline Defatted rice offal & - & - & 40 & 90 \\
\hline Soya-bean meal & - & I40 & 90 & 20 \\
\hline White fish meal & 90 & 60 & 40 & 10 \\
\hline Lucerne meal & - & - & 25 & 50 \\
\hline Skim milk & 300 & 50 & - & - \\
\hline Dried brewer's yeast & 20 & 20 & - & - \\
\hline Glucose & 140 & - & - & - \\
\hline Sucrose & 20 & 20 & - & - \\
\hline Calcium carbonate & - & 6 & 7 & Io \\
\hline Dicalcium phosphate & - & 8 & - & - \\
\hline Tricalcium phosphate & 7 & - & 8 & 5 \\
\hline Sodium chloride & 3 & 4.5 & 5 & 5 \\
\hline Vitamin and mineral mixture* & 5 & 5 & - & - \\
\hline Vitamin and mineral mixture $\dagger$ & $\underline{-}$ & ב & $2 \cdot 5$ & 2.5 \\
\hline DL-methionine & - & I & I & 1 \\
\hline
\end{tabular}

* Providing (/kg diet): retinol $22.5 \mathrm{mg}$, cholecalciferol $25 \mu \mathrm{g}$, thiamin $1.5 \mathrm{mg}$, riboflavin $5 \mathrm{mg}$, cyanocobalamin $12 \mu \mathrm{g}$, pantothenic acid $15 \mathrm{mg}$, nicotinic acid $30 \mathrm{mg}$, choline $500 \mathrm{mg}$, manganese $50 \mathrm{mg}$, zinc I $50 \mathrm{mg}$, copper $200 \mathrm{mg}$, iron $100 \mathrm{mg}$, iodine I $\mathrm{mg}$.

$\dagger$ Providing ( $/ \mathrm{kg}$ diet): retinol $30 \mathrm{mg}$, cholecalciferol $50 \mu \mathrm{g}$, thiamin $0.5 \mathrm{mg}$, riboflavin $3.5 \mathrm{mg}$, pyridoxine $0.25 \mathrm{mg}$, pantothenic acid $5.5 \mathrm{mg}$, nicotinic acid $3 \mathrm{mg}$, choline $28.8 \mathrm{mg}$, manganese $50 \mathrm{mg}$, zinc $60 \mathrm{mg}$, copper $10 \mathrm{mg}$, iron $50 \mathrm{mg}$, iodine I $\mathrm{mg}$.

Table 2. Chemical composition of the standard (diets $A-D)$ and the commercial (diets $E-H)$ diets $(\mathrm{g} / \mathrm{kg})^{*}$

\begin{tabular}{lrrrrrrrr} 
& \multicolumn{10}{c}{ Diet } \\
\cline { 2 - 9 } & A & B & C & D & E & F & G & H \\
Dry matter & 878 & 870 & 870 & 863 & 873 & 859 & 861 & 862 \\
Crude protein (nitrogen $\times 6 \cdot 25)$ & 247 & 203 & $15 I$ & 132 & 195 & 188 & 163 & 159 \\
Crude fat & 37 & 33 & 31 & 27 & 52 & 45 & 47 & 36 \\
N-free extract & 536 & 568 & 584 & 600 & 559 & 555 & 579 & 572 \\
Crude fibre & 3 & 17 & 43 & 55 & 20 & 28 & 28 & 51 \\
Ash & 55 & 49 & 6 I & 49 & 47 & 43 & 44 & 44
\end{tabular}

* All the diets contained I $\mathrm{g}$ chromic oxide $/ \mathrm{kg}$; for details of ingredients, see Table I.

immediately after preparation or after storing for 15,40 or $60 \mathrm{~d}$ at $-20^{\circ}$, was used for in vitro digestibility determination conducted by the standard procedures.

Expt 4 . Effect of sample size on in vitro digestibility. Two sample sizes, 0.5 and $1 \mathrm{~g}$, were tested with the four standard diets. The incubation conditions were identical to the standard procedures.

Expt 5. Effect of diet particle size on in vitro digestibility and the relationships between in vitro and in vivo digestibilities. The in vitro DM and CP digestibilities in the eight diets were compared with those obtained from in vivo digestibility experiments. Moreover, since test diets differed considerably in their fineness of grinding, the effect of grinding on in vitro digestibility was investigated. Each diet was ground in a laboratory mill with a I mm screen. The digestibilities of the original and ground diet were compared. The incubation conditions in the in vitro digestion were identical to the standard procedures. 


\section{In vivo digestion study}

Eight Landrace $\times$ Large White cross-bred male pigs, weighing approximately $20 \mathrm{~kg}$ at the beginning of the experiment were used for in vivo digestion studies (trials I and 2). They were maintained in metabolism cages. In trial I, four pigs were given the standard diets shown in Tables $I$ and 2, and in trial 2 the other four were given the commercial diets shown in Table 2. Each trial contained four periods of $10 \mathrm{~d}$ each. The four diets were fed rotationally to each pig. The pigs were given $40 \mathrm{~g}$ diet $/ \mathrm{kg}$ body-weight once daily at 08.30 hours. Drinking-water was freely available. After the $6 \mathrm{~d}$ preliminary feeding, all faeces were collected for the following $4 \mathrm{~d}$, dried in a forced-air oven at $60^{\circ}$, air-equilibrated, ground and sampled for analysis. The digestibilities of DM and CP were determined by the chromic oxide method.

\section{Standard procedures in in vitro digestion study}

The method had two stages. In the first stage, $0.5 \mathrm{~g}$ duplicate samples of each diet were weighed into $100 \mathrm{ml}$ Erlenmeyer flask, to which $20 \mathrm{mg}$ pepsin in $10 \mathrm{ml} \mathrm{0.075} \mathrm{M-hydrochloric}$ acid were added and incubated with shaking at 80 oscillations/min for $4 \mathrm{~h}$ at $37^{\circ}$ in a waterbath. At the end of the first incubation period, the contents were neutralized with $0.2 \mathrm{M}$ sodium hydroxide.

In the second stage, $10 \mathrm{ml}$ intestinal fluid prepared as mentioned previously were added and the digestion mixtures were incubated for an additional $4 \mathrm{~h}$ at $37^{\circ}$.

At the completion of the second incubation the contents of the flask were transferred to $\mathrm{I} 20 \mathrm{ml}$ centrifuge-tube and centrifuged immediately for $\mathrm{I} 0 \mathrm{~min}$ at $\mathrm{I} 250 \mathrm{~g}$. The supernatant fraction was discarded. The precipitate was resuspended in $50 \mathrm{ml}$ water and recentrifuged for 10 min at $1250 \mathrm{~g}$. The second supernatant fraction was discarded. The insoluble residue in the tube was mixed with a little water and filtered through a weighed filter paper (Toyo-Roshi No. 5A, Toyo-Roshi, Tokyo, Japan). Experience has shown that the filtration will be difficult if the digestion fluid is not removed and the precipitate washed. The paper containing the residue was dried for $5 \mathrm{~h}$ at $105^{\circ}$ and transferred to a Kjeldahl flask for determination of CP. The digestibilities of DM and CP were calculated:

$$
\mathrm{I}-\frac{R}{S}
$$

where $R$ is the weight of the oven-dry sample residue and $S$ is the weight of the oven-dry sample for each constituent.

$$
\text { Chemical analysis }
$$

Chromic oxide was determined colorimetrically using the method of Brisson (1956). Other constituents in the food and faeces were determined by the methods of the Association of Official Analytical Chemists (1970).

\section{RESULTS}

Expt 1 . Effect of pepsin concentration and incubation period in the first stage of the in vitro method. The results of both variables are given in Fig. I. When the pepsin concentration was increased from $O \cdot I$ to $2 \mathrm{~g} / 1$, the digestibility in both $\mathrm{DM}$ and $C P$ increased for diet $D$, while for diet $A$ the pepsin concentration caused almost no effect on in vitro digestibility in either DM or CP. Considering the effect of pepsin concentration on values for diet $D$, $2 \mathrm{~g} / \mathrm{l}$ was used in the standard procedure.

Incubation period had little effect on the in vitro digestibility for DM, although a slight increase in DM digestibility occurred when the incubation period was increased from 0 to $2 \mathrm{~h}$. In contrast, $\mathrm{CP}$ digestibility for diet $\mathrm{D}$ increased as the incubation period was increased from 0 to $4 \mathrm{~h}$. There was a difference of $0.02 \mathrm{I}$ and 0.013 digestibility units between 2 and 


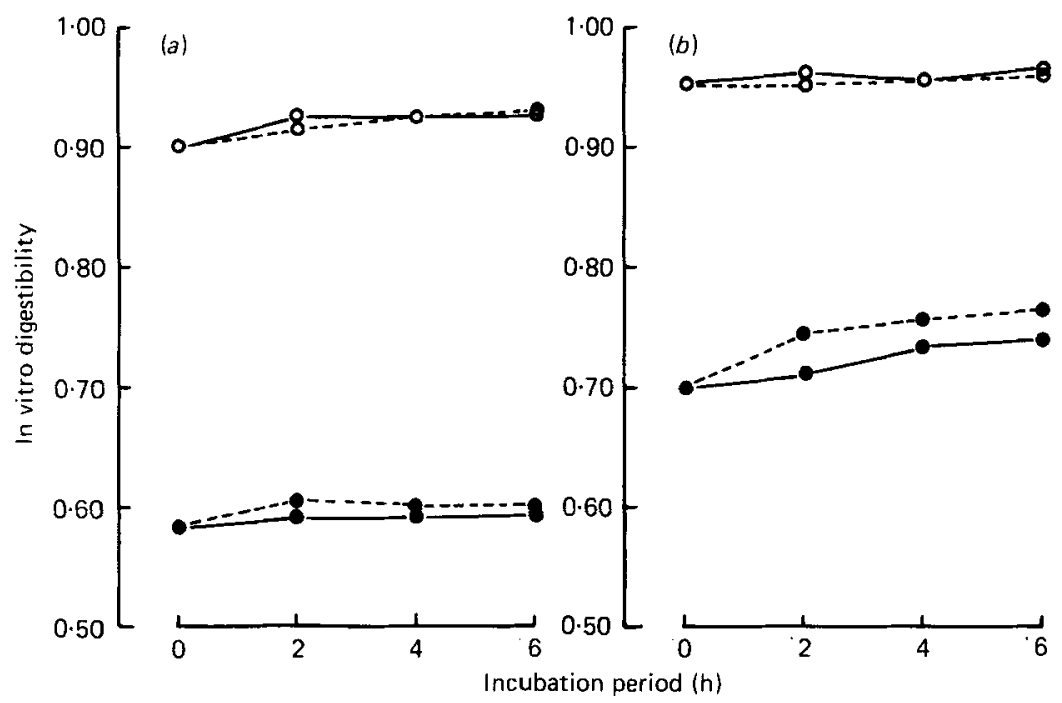

Fig. I. Expt I. Effect of pepsin (EC 3.4.4. I) concentration (o. I g/1 (-) or $2 \mathrm{~g} / 1(---))$ and incubation period $(h)$ in the first stage of the in vitro method on in vitro $(a)$ dry matter and $(b)$ crude protein (nitrogen $\times 6.25$ ) digestibilities for the standard diets $A(O)$ and $D(O)$. After the first-stage incubation, the second-stage incubation was conducted with intestinal fluid for $4 \mathrm{~h}$ at $37^{\circ}$. Mean values for duplicate determinations. For details of diets and procedures, see p. 5 I 2 and Tables $\mathrm{I}$ and 2.

$4 \mathrm{~h}$ incubation periods at pepsin concentrations of $\mathrm{O} \cdot \mathrm{I}$ and $2 \mathrm{~g} / \mathrm{l}$ respectively. Contrary to diet $\mathrm{D}$, the value for diet $\mathrm{A}$ was high, 0.952 , even at $\mathrm{O} h$ incubation period and did not increase further with the incubation time.

Judging from the result in CP digestibility of diet D, a $4 \mathrm{~h}$ incubation period was selected as the first stage experimental condition of the standard procedure.

Expt 2. Effect of incubation period in the second stage of the in vitro method. The results are given in Fig. 2. The DM digestibility for all the diets increased remarkably in a hyperbolic manner as the incubation period was increased from $o$ to $6 \mathrm{~h}$. Digestibility for the o $\mathrm{h}$ incubation period, approximately 0.30 with diets $\mathrm{B}, \mathrm{C}$ and $\mathrm{D}$, is a measure of the extent of the first stage digestion. These digestibilities increased more than $100 \%$ with $6 \mathrm{~h}$ incubation. These results indicate that, for DM digestion, the second stage incubation with the intestinal fluid played an important role in the digestion of these tested diets. In the instance of diet A, 0.719 of its DM was digested at $\mathrm{oh}$ incubation.

As for CP digestibility, although some increases occurred when the incubation period was increased from 0 to $4 \mathrm{~h}$, the extent of the increase was less than that for DM. The results indicated that most of the digestible CP in all the diets tested was digested or solubilized before the second stage.

There were no significant differences in the DM or CP digestibility between 4 and $6 \mathrm{~h}$ incubation. Thus, $4 \mathrm{~h}$ was selected as the incubation period in the second stage of the standard procedure. This selected incubation period was comparable to the small intestinal retention times of markers, 3-5 h, reported by Keys \& DeBarthe (1974) and Furuya \& Takahashi (1975a).

Expt 3. Effect of storing of the intestinal fluid on in vitro digestibility. The results given in Fig. 3 indicated that storing the intestinal fluid at $-20^{\circ}$ for at least $60 \mathrm{~d}$ had little effect on digestibility of DM or CP. 
(a)

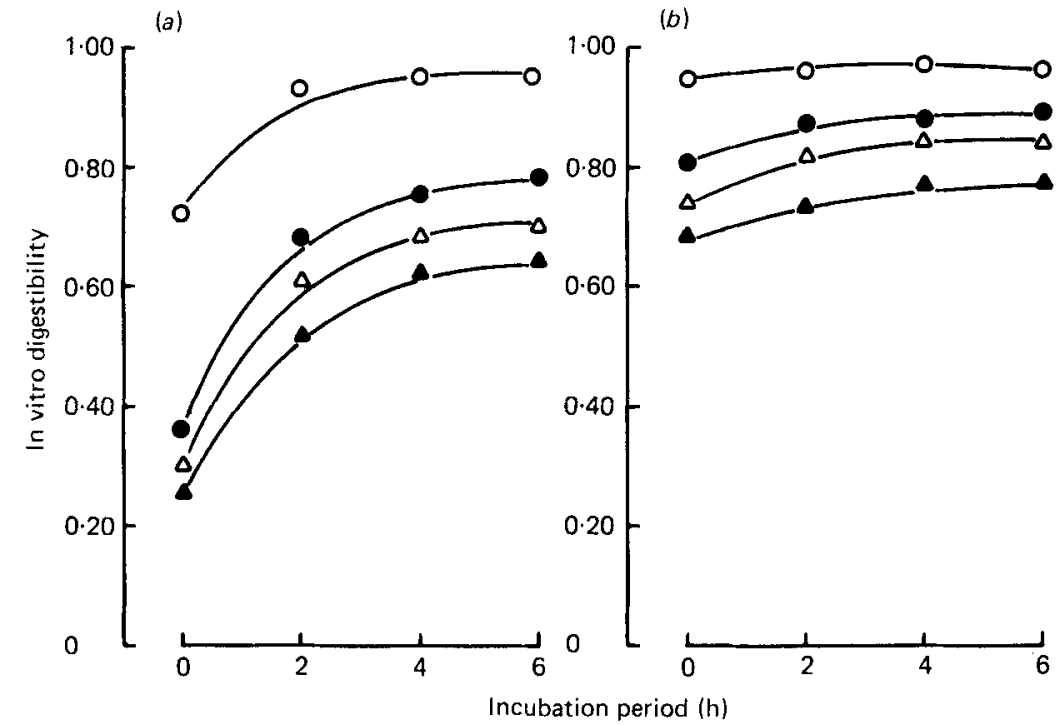

Fig. 2. Expt 2. Effect of incubation period (h) in the second-stage of the in vitro method on in vitro (a) dry matter and $(b)$ crude protein (nitrogen $\times 6.25$ ) digestibilities in the standard diets $\mathrm{A}(\mathrm{O})$, $\mathrm{B}(\bullet), \mathrm{C}(\triangle)$ and $\mathrm{D}(\boldsymbol{A})$. The first-stage incubation was conducted with acid pepsin (EC 3.4.4.I) $\left(2 \mathrm{~g} / \mathrm{l} 0.075 \mathrm{M}\right.$-hydrochloric acid) for $4 \mathrm{~h}$ at $37^{\circ}$ before the second-stage incubation. Mean values for duplicate determinations. For details of diets and procedures, see p. 512 and Tables 1 and 2.

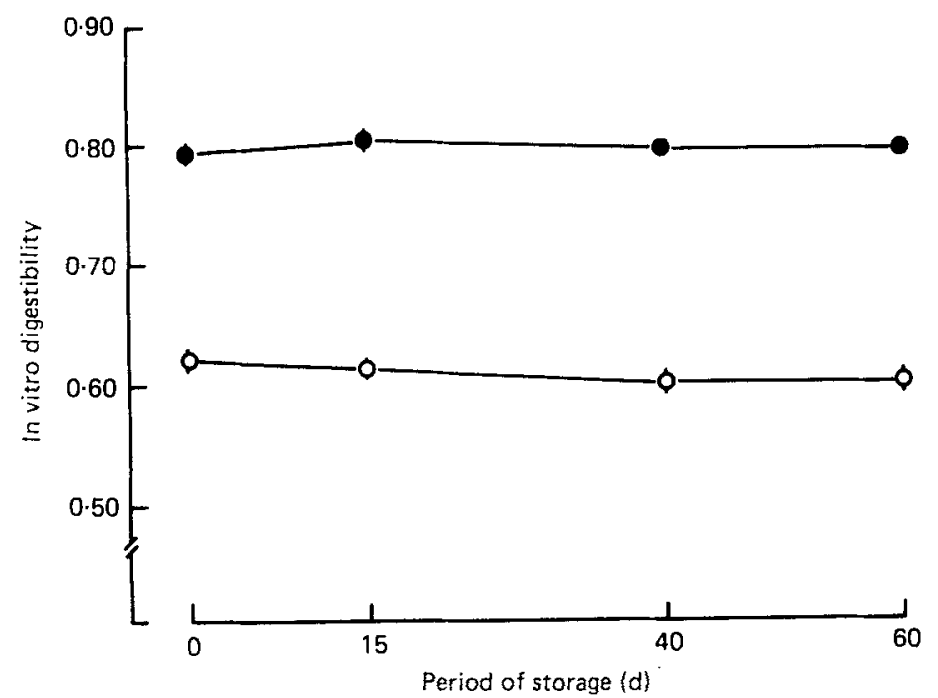

Fig. 3. Expt 3. Effect of storing intestinal fluid at $-20^{\circ}$ on in vitro dry matter $(O)$ and crude protein (nitrogen $\times 6.25$ ) $(\bullet)$ digestibilities in the standard diet $C$. Mean values for duplicate determinations, with their standard errors represented by vertical bars. For details of diet and procedures, see p. 512 and Tables I and 2. 
Table 3. Expt 4. Effect of sample size $(\mathrm{g})$ on in vitro digestibility in the standard diets* (Mean values with their standard errors for duplicate measurements)

In vitro digestibility of:

\begin{tabular}{|c|c|c|c|c|c|c|c|c|}
\hline \multirow{2}{*}{\multicolumn{2}{|c|}{ Sample size $(\mathrm{g})$}} & \multicolumn{3}{|c|}{ Dry matter } & \multicolumn{4}{|c|}{ Crude protein } \\
\hline & & 0.5 & \multicolumn{2}{|c|}{$\mathbf{I}$} & \multicolumn{2}{|c|}{0.5} & \multicolumn{2}{|c|}{ I } \\
\hline Diet & Mean & SE & Mean & $\mathrm{SE}$ & Mean & SE & Mean & SE \\
\hline A & 0.910 & 0.004 & 0.864 & 0.001 & 0.956 & 0.001 & 0.940 & 0.001 \\
\hline B & 0.689 & 0.003 & 0.595 & 0.003 & 0.848 & 0.008 & 0.799 & 0.004 \\
\hline $\mathrm{C}$ & 0.630 & 0.001 & 0.571 & 0.001 & 0.814 & 0.006 & 0.762 & 0.001 \\
\hline $\mathrm{D}$ & 0.562 & 0.003 & 0.486 & 0.001 & 0.738 & 0.010 & 0.700 & 0.006 \\
\hline
\end{tabular}

* For details of diets and procedures, see p. 512 and Tables $I$ and 2.

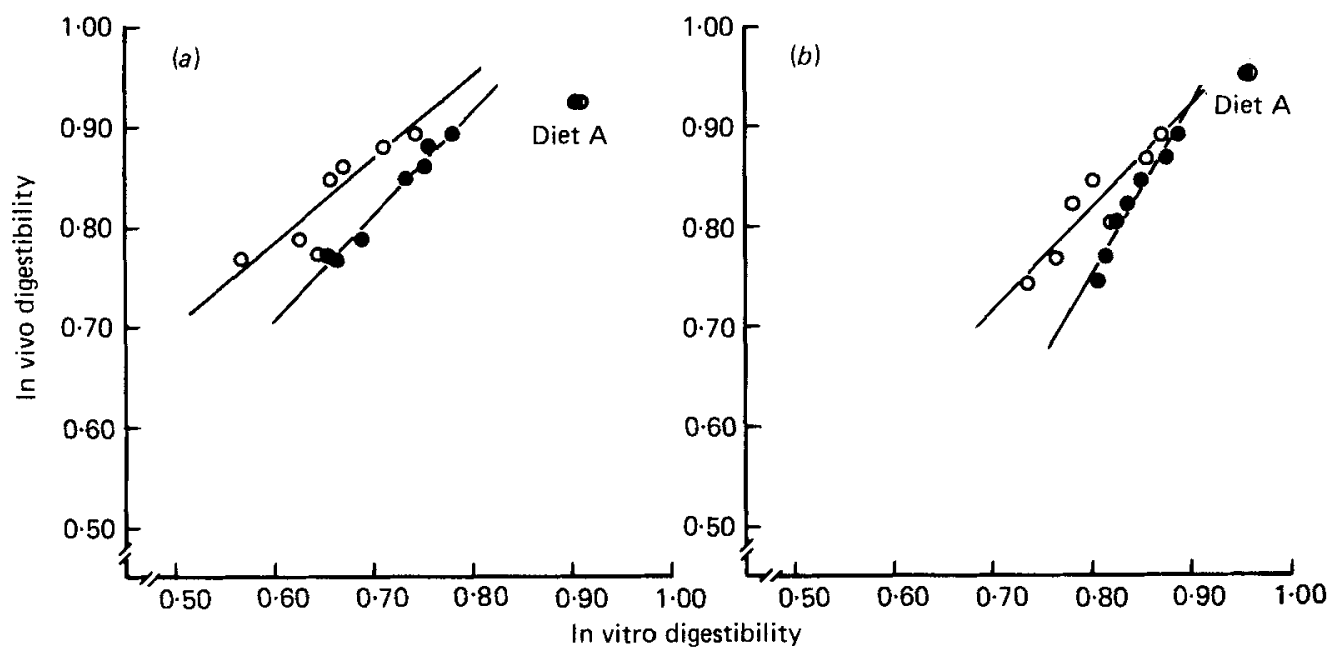

Fig. 4. Expt 5. Relationships between in vivo and in vitro digestibilities of (a) dry matter and $(b)$ crude protein (nitrogen $\times 6.25$ ) when the original samples $(O)$ or the samples ground to pass through a $1 \mathrm{~mm}$ screen (C) were used for the in vitro digestibility determination. Mean values for duplicate determinations for the in vitro method and for four pigs for the in vivo method. For details of in vitro and in vivo digestibility determination, see p. 512 and p. 514 respectively.

Expt 4. Effect of sample size on in vitro digestibility. The results are shown in Table 3. With the assay procedures used, the smaller sample size $(0.5 \mathrm{~g})$ was shown to result in a higher digestibility for both $\mathrm{DM}$ and $\mathrm{CP}$ for all diets. Although identical digestibilities may be obtained when the volumes of the incubation solutions are increased along with the weight of sample, the small size minimizes the quantity of pepsin and intestinal fluid and incubator space required. Consequently, in the standard procedures $0.5 \mathrm{~g}$ was chosen as the sample size.

Expt 5. Effect of diet particle size on in vitro digestibility and the relationships between in vitro and in vivo digestibilities. Fig. 4 shows the relationships between in vivo and in vitro digestibilities in DM and CP. The in vivo digestibilities of the original samples were plotted along the $Y$ axis, and the in vitro digestibilities of both original and ground samples along the $X$ axis.

When original and ground samples of the same diet were compared additional grinding 
increased in vitro digestibility in both DM and $\mathrm{CP}$, except for diet $\mathrm{A}$. This increase of in vitro digestibility by additional grinding was more marked in samples of low initial digestibility and of coarse texture. In diet A neither value for in vitro digestibility was increased by additional grinding. This is assumed to be due to the original fineness and high digestibility of diet A.

For original samples, linear regression equations $Y=0.83 X+0.2847(r 0.89, P<0.01$, residual standard deviation (RSD) \pm 0.027$)$ and $Y=\mathrm{I} .0 \mathrm{I} X+0.0076(r 0.9 \mathrm{I}, P<0.0 \mathrm{I}$, RSD \pm 0.024 ) could be fitted to the values for DM and CP respectively for the seven tested diets. In this calculation, the values for diet $\mathrm{A}$ were excluded because the ingredients, chemical composition and physical form (particle size) of this diet were considerably different from those of the other diets and, as a result, the relationships between in vivo and in vitro digestibilities were different from those of the other diets, as shown in Fig. 4.

When ground samples were used for in vitro digestibility determination, linear regression equations $Y=\mathrm{I} .04 X+0.0806(r 0.98, P<0.0 \mathrm{I}, \mathrm{RSD} \pm 0.0 \mathrm{II})$ and $Y=\mathrm{I} \cdot 70 X-0.6092$ ( $r 0.98, P<0.01, \mathrm{RSD} \pm 0.0 \mathrm{I} 2)$ for $\mathrm{DM}$ and $\mathrm{CP}$ respectively were obtained. Also, in these calculations, the values for diet A were excluded.

The RSD of the regression for ground samples was smaller than for original samples for both DM and CP digestibility. This result indicated that samples submitted for in vitro digestibility determination should be ground to a particle size of less than I $\mathrm{mm}$ for a reasonable prediction of in vivo digestibility.

\section{DISCUSSION}

This in vitro method gives a good estimate of in vivo digestibility as shown by the correlation coefficients of 0.98 obtained in Expt 5, when samples of diets are additionally ground to a small particle size.

The use of the present method for the estimation of in vivo digestibility has many advantages. This method requires small amounts of sample and uses no special apparatus, and many samples can be handled in a single experiment; in our laboratories eight to sixteen samples of unknown digestibility, together with four standard diets, are analysed in duplicate in each trial. The period of time required is very short; determinations for DM and CP digestibility are usually completed within $2 \mathrm{~d}$.

This method is reproducible as shown in Table 3. The average standard errors were: \pm 0.0027 (DM) and $\pm 0.007 \mathrm{I}$ (CP) digestibility units for $0.5 \mathrm{~g}$ sample size; \pm 0.0017 (DM) and \pm 0.0036 (CP) digestibility units for I $g$ sample size. Also, this method is accurate, considering that the RSD of the regression of in vivo on in vitro is a measure of the error of prediction for comparing laboratory methods. The RSD of the regression for DM digestibility in the present method, $\pm 0.0 \mathrm{I}$, is comparable to the values calculated from the two-stage in vitro techniques used for the evaluation of ruminant foods, in which the deviations ranged from \pm 0.0142 to \pm 0.0380 (Osbourn \& Terry, 1977).

The major problem in the routine use of the rumen fluid-pepsin method described by Tilley \& Terry (1963) has been maintaining uniform activity in the rumen fluid and the need for fresh preparations (Osbourn \& Terry, 1977). In contrast, the intestinal fluid used in the present method could be preserved for at least 2 months without any obvious change in its activity for both DM and CP digestion (see Fig. 3). Therefore, the intestinal fluid obtained each day can be pooled, which eliminates day-to-day variation in activity of the intestinal fluid. In addition, a recent study (S. Furuya \& K. Sakamoto, unpublished results) has indicated that the activity of the intestinal fluid for DM and CP digestibilities could be maintained when the fluid was lyophilized and reconstituted in water. This indicates that it is not even necessary to keep a host animal in each laboratory.

Although the in vitro digestibilities obtained with the present method were highly cor- 
related with those from in vivo studies, as shown in Expt 5 , there was an obvious dissimilarity between the two methods. For DM, the in vivo digestibilities tended to be higher than the in vitro values, and for $\mathrm{CP}$ a reverse relationship, i.e. higher in vitro measurements, was shown when ground samples were used in the in vitro experiment (see Fig. 4). These observations indicated that to increase the accuracy of the in vitro method, some standard samples of known in vivo digestibilities should be included in each in vitro experiment and their values should be used for corrections.

The higher in vivo DM digestibility may be explained by the observation that digestion of fibrous substances which usually occurs in the large intestine of pigs was not considered in the present in vitro method. The digestibility obtained by the present method essentially corresponds to the in vivo digestibility at the terminal ileum. For all diets except $A$, the in vitro DM digestibility was $0.10-0.13$ digestibility units lower than in vivo measurements, even when ground samples were used in the in vitro experiment. These dfferences were comparable to those found between the in vivo digestibility in the whole digestive tracts and the in vivo digestibility at the terminal ileum, i.e. $0 \cdot 15-0 \cdot 16$ digestibility units which was reported by Furuya \& Takahashi (1975a). In the instance of diet A, which had a very low crude fibre content, $3 \mathrm{~g} / \mathrm{kg}$, in vivo and in vitro digestibilities were identical.

The lower in vivo CP digestibility may be explained by the observation that animal faeces include $\mathrm{N}$-containing endogenous products, in addition to undigested food residues. In contrast, a minimum of these endogenous substances are present in the in vitro method.

At the present time there are some limitations to the in vitro method. First, the efficiency of the intestinal fluid in digesting diets may be influenced by the diet of the host animal. In the in vitro method pancreatic enzymes contained in the intestinal fluid are considered to play an important role in digestion, since the major part of intestinal digestion in the lumen is the result of pancreatic enzyme activities (Rerat et al. 1976). The secretion of pancreatic enzymes into the intestinal lumen has been reported to change in response to changes in the intake of dietary protein (Snook \& Meyer, r964). Corring \& Saucier (1972) have demonstrated that the activity of chymotrypsin (EC 3.4.4.5) varies greatly according to the protein content of the diet. Although the introduction of some standard samples of known in vivo digestibility in the in vitro experiments may minimize the influence of the diet given to the host animal, this limitation remains to be investigated.

Secondly, any digestion occurring in the large intestine, such as that of fibrous material, is excluded from measurement by this method. It is probable then that had samples containing a higher crude fibre content such as roughage been examined, the correlation in DM digestibility with in vivo digestibility would have been lower than that obtained in the present study. For more exact prediction of in vivo DM digestibility of diets with a high roughage content it may be possible to add a third digestion stage for crude fibre digestion to the present two-step procedure. Such an addition could be a cellulase preparation, although additional procedure prolongs the period of time required for digestibility measurements.

The authors thank Mrs F. Usui for performing the operation and for the care of the host animal, and Dr K. Kameoka for supervision. They also thank Dr Nancy R. Stevenson, C.M.D.N.J.-Rutgers Medical School, for her valuable comments on the manuscript and her help with the English language.

\section{REFERENCES}

Akeson, W. R. \& Stahmann, M. A. (1964). J. Nutr. 83, 257.

Association of Official Analytical Chemists (I970). Official Methods of Analysis, IIth ed. Washington, DC: Association of Official Analytical Chemists.

Brisson, G. J. (1956). Can. J. agric. Sci. 36, 2 I0. 
Corring, T. \& Saucier, R. (1972). Annls Biol. anim. Biochem. Biophys. 12, 233.

Furuya, S. \& Takahashi, S. (1975a). Jap. J. zootech. Sci. 46, 630.

Furuya, S. \& Takahashi, S. (1975b). Br. J. Nutr. 34, 267.

Holmes, J. H. G., Bayley, H. S. \& Horney, F. D. (1973). Br. J. Nutr. 30, 401.

Keys, J. E. Jr \& DeBarthe, J. V. (1974). J. Anim. Sci. 39, 57.

Osbourn, D. F. \& Terry, R. A. (1977). Proc. Nutr. Soc. 36, 2 I 9.

Rerat, A., Corring, T. \& Laplace, J. P. (1976). In Protein Metabolism and Nutrition, pp. 97-138. [D. J. A.

Cole, K. N. Boorman, P. J. Buttery, D. Lewis, R. J. Neale and H. Swanson, editors]. London and Boston: Butterworths.

Snook, J. T. \& Meyer, J. H. (1964). J. Nutr. 82, 409.

Tilley, J. M. A. \& Terry, R. A. (1963). J. Br. Grassld Soc. 18, 104. 